MIDPI

sciforum

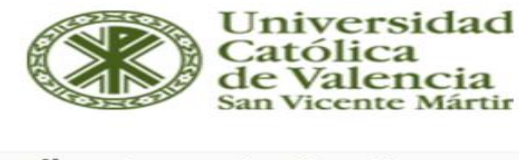

A $>$ International > About us

\section{International}

\section{IWIMSM-03: Iberoamerican Workshop on} Model. and Simulation Methods, Valencia, Spain, 2019

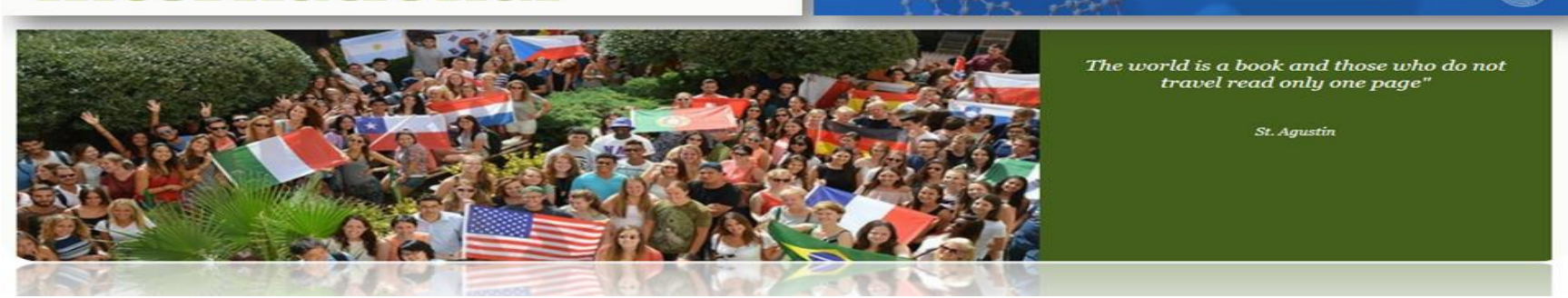

\title{
Invisible training: how to improve your sports performance
}

\author{
E. Drehmer Rieger ${ }^{a *}$, S. Carrera Juliáb ${ }^{b}$ M.A. Navarro Moreno ${ }^{c}$ and M.L. Moreno \\ Sancho $^{c}$
}

aDepartament Health Sciences, Catholic University of Valencia "San Vicente Mártir", Torrente, Valencia, Spain

bepartament of Nutrition and Dietetics, Catholic University of Valencia "San Vicente Mártir", Valencia, Spain

${ }^{c}$ Departament of Basic Sciences, Catholic University of Valencia "San Vicente Mártir”, Torrente, Valencia, Spain

\begin{tabular}{|c|c|c|c|c|c|}
\hline \multicolumn{5}{|c|}{ Graphical Abstract } & \multirow{3}{*}{$\begin{array}{l}\text { Abstract. } \\
\text { Athletes of all levels, from professionals to } \\
\text { amateurs, are looking for ways to improve both } \\
\text { performance and health. These not only involves } \\
\text { training tasks, but also those aspects that can } \\
\text { influence both performance improvement and } \\
\text { injury prevention. These aspects are known as } \\
\text { invisible training. Invisible training will improve } \\
\text { the recovery between sessions, reduce the risk of } \\
\text { injury and better assimilate the training. The } \\
\text { assumption of these basic measures, together } \\
\text { with mental and physical training, will be } \\
\text { decisive for sports performance. For example, in } \\
\text { endurance sports, training load, nutrient intake } \\
\text { and sleep are key factors that modulate immune }\end{array}$} \\
\hline \begin{tabular}{c|} 
SPORTS \\
PERFORMANCE
\end{tabular} & & $\begin{array}{l}\text { PHYSICAL } \\
\text { TRAINING }\end{array}$ & + & $\begin{array}{l}\text { INVISIBLE } \\
\text { TRAINING }\end{array}$ & \\
\hline$\underset{\substack{\text { Less injuries } \\
\text { Better results }}}{\bigoplus}$ & & & & 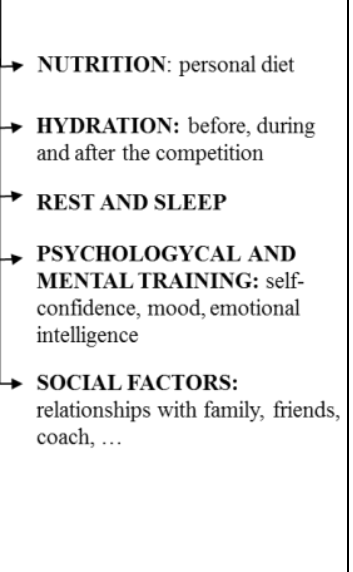 & \\
\hline
\end{tabular}


function, positively or negatively. Regular physical activity as well as a balanced diet and sufficient sleep are associated with improved immune function. On the other hand, prolonged or too intense exercise, energy deficit and lack of sleep decrease the function of the immune system and increase the probability of suffering from infections and pathologies. Therefore, psychological training, rest, nutritional and hydration habits and social aspects will be a necessary activity for the technical managers of a sport, if they wish to achieve medium or longterm physical objectives.

\section{References}

- Cosca, D. D., \& Navazio, F. (2007). Common problems in endurance athletes. American Family Physician, 76(2), 237-244.

- Llovet Riera, M. (1989). L'entrenament invisible/ The Invisible Training. Apunts: Educacion Fisica y Deportes, (15), 37-47.

- Louis, J., Marquet, L.-A., Tiollier, E., Bermon, S., Hausswirth, C., \& Brisswalter, J. (2016). The impact of sleeping with reduced glycogen stores on immunity and sleep in triathletes. European Journal of Applied Physiology, 116(10), 1941-1954.

Nereis: https://www.ucv.es/investigacion/publicaciones/catalogoderevistas/revistanereis 